\title{
Análise descritiva dos verbos psicológicos do português brasileiro $^{1}$
}

\author{
Márcia Cançado \\ Universidade Federal de Minas Gerais
}

\section{Abstract}

This paper presents a descriptive analysis of the psychological verbs in Brazilian Portuguese. A new classification for these verbs is proposed: in the current literature we find two classes of psychverbs; I propose four different classes based on a fine-grained approach of thematic relations. Also, I make a thorough revision of many syntactic and semantic properties of psych-verbs. According to this analysis, I present some clues towards a semantic approach to the problems related to those verbs.

As there are interesting questions related to psych-verbs concerning the organization of argument structure, I hope the data presented are useful to other researchers from different lines, working with Brazilian Portuguese. 


\section{INTRODUÇÃO}

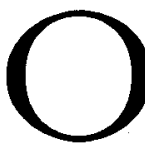

$s$ verbos chamados psicológicos, ou seja, verbos que denotam um estado emocional e têm, obrigatoriamente, um argumento experienciador, apresentam interessantes propriedades relacionadas à organização da estrutura argumental e à ligação de anáforas, sendo assim um interessante objeto de estudo para pesquisadores de teoria lingüística.

Por isso, proponho neste artigo uma ampla revisão das propriedades sintáticas e semânticas desses verbos em português brasileiro. Um dos primeiros pontos será mostrar, através de uma análise descritiva dos dados do português, uma nova classificação para os verbos psicológicos, diferente da apontada para outras línguas pela literatura. Isso será feito pelas análises de propriedades sintáticas e redes temáticas desses verbos. Também serão mostrados alguns indícios de que certos aspectos semânticos são relevantes para a sintaxe de certas expressões das línguas naturais. (Baseandose nesses indícios, esses resultados descritivos foram precisados e, em parte, formalizados em Cançado (1995a), dentro do quadro teórico de uma semântica representacional (Jackendoff, 1990; Franchi, 1975), e, sob essa abordagem, foram respondidas várias questões que se colocaram durante a análise descritiva, e questões também já feitas anteriormente na literatura.)

Os resultados que aqui serão apresentados são baseados em uma pesquisa exaustiva e abrangente (mais de 4000 exemplos armazenados, e os dados cruzados via D-BASE). ${ }^{2}$ Como essa descrição parece-me consideravelmente sólida do ponto de vista empírico, retratando de uma maneira real o que acontece com os verbos psicológicos no português brasileiro, um segundo objetivo 
deste artigo é tornar acessíveis esses resultados e os problemas levantados durante essa análise para outros pesquisadores de linhas teóricas diferentes. Com isso, espero estimular outros trabalhos sobre o português que possam ser confrontados com a solução representacional proposta em Cançado (1995a), e acrescentar novos focos de luz a essa investigação semântica.

\section{OS VERBOS PSICOLÓGICOS}

As anômalas propriedades atribuídas aos verbos psicológicos (ou, tomando como empréstimo do inglês, "psico-verbos") são as seguintes: primeiramente, o argumento que recebe o papel temático de Experienciador pode aparecer tanto na posição de sujeito como na posição de objeto na estrutura superficial (estrutura-S) desses verbos, parecendo ser essa escolha aleatória. Com isso, na literatura da rea, esses verbos são divididos em duas classes:

(1) Mário teme fantasmas. Exp Tema

(2) Fantasmas assustam Mário. Tema Exp

Nos exemplos acima, tem-se que, em (1), a pessoa que sofre o estado emocional de medo, o Experienciador (Exp), é o sujeito; e, em (2), a pessoa que sofre o mesmo estado emocional, o Exp, é o objeto. Não se encontram facilmente pares sinônimos de verbos transitivos com essa alternância de argumentos:
(3) João quebrou o vaso. Ag Tema
(4)*O vaso ??? João.
Tema Ag

Uma segunda característica é o problema apresentado pelos verbos psicológicos, mais particularmente aqueles com o Exp na 
posição de objeto, que permitem a ligação de anáforas de uma maneira não usual: a anáfora localizada no sujeito pode ser ligada, ou pode tomar como antecedente o objeto desse verbo:

(5) Estórias sobre si mesma ${ }_{1}$ agradam muito Maria ${ }_{i}$.

(6) Falatórios sobre si mesmo incomodam João.

Dentro do quadro da Teoria da Regência e Vinculação, podese dizer que exemplos como esses violam a condição de c-comando. Uma anáfora deve ser c-comandada por seu antecedente. Como afirma a literatura, essa condição funciona, sistematicamente, para outros verbos transitivos, não funcionando apenas para aqueles verbos que têm o Exp na posição de objeto:

(7)*Estórias sobre si mesma ${ }_{i}$ retratam Maria muito bem.

(8)*Falatórios sobre si mesmo ${ }_{1}$ descrevem João que uma biografia.

É devido a esse diferente comportamento que esses verbos têm sido freqüentemente objeto de estudo da sintaxe e semântica (Postal, 1971; Ruwet, 1972; Oliveira, 1979; Pesetsky, 1987; Belletti \& Rizzi, 1988; Baker, 1988; Legendre, 1989; Grimshaw, 1987 e 1990; van Voorst, 1992; Zubizarreta, 1992; ver também análises sobre Grimshaw e Belletti \& Rizzi, respectivamente, em Cançado, 1995b e no prelo). $O$ estudo desses verbos tem muito a dizer a pesquisadores que se interessem pela organização da estrutura argumental.

\section{DELINEAMENTO DA PESQUISA}

Como foi visto acima, os problemas envolvendo a seleção argumental ${ }^{3}$ colocam-se em bastante evidência nos verbos psicológicos. Portanto, para fazer a análise descritiva desses verbos, baseei-me na estratégia de pesquisa, proposta por Dowty (1991), sobre os papéis temáticos e seleção argumental. Em síntese, o autor propõe que convém, inicialmente, separar as observações sobre 
eventuais papéis temáticos em fronteiras naturais, na medida em que se possa justificar divisões não arbitrárias entre elas. Assim, podese trabalhar sobre cada domínio em separado, sem fazer interferirem informações e concepções provindas de outros domínios. Pode-se, por exemplo, distinguir o que se situa no quadro das observações léxico-estruturais de Jackendoff (1972) e Gruber (1965); o que se determina pela análise dos fatos de seleção argumental; o que se forma na perspectiva gerativista (ou gramática léxico-funcional) com vistas à indexação dos argumentos para a projeção sintática, e assim por diante. $\mathrm{O}$ autor, em seu texto, escolhe operar sobre o domínio demarcado pelo critério da seleção argumental. Adotei essa estratégia de pesquisa pensando em obter um melhor conhecimento sobre as questões empíricas relativas a esses verbos, utilizando para essa investigação o domínio da seleção argumental assumido pelo autor, além também do estudo da diátese verbal. ${ }^{4}$

O corpus em que foi baseado este artigo, a princípio, compreendia 360 verbos caracterizados como psicológicos e inúmeros exemplos com os mesmos. Esses verbos e exemplos foram extraídos de um dicionário de verbos (Borba, 1990), ${ }^{5}$ de um dicionário de língua portuguesa (Ferreira, 1975), de exemplos de uma tese de doutorado sobre verbos psicológicos do português de Portugal (Oliveira, 1979), e de meus próprios exemplos. Segui, pois, a tradição gerativista que se baseia na intuição do pesquisador para a avaliação da aceitabilidade e gramaticalidade das expressões de sua língua. Usei essa intuição de falante nativo e recorri também a terceiros quando havia dúvidas. Certamente, ainda haverá exemplos que são questionáveis quanto à sua aceitabilidade e gramaticalidade, mas para a análise desejada representarão uma pequena porcentagem na totalidade dos dados, não comprometendo, assim, a confiabilidade dos resultados.

Em uma primeira análise, utilizando para o armazenamento dos dados o programa D-Base, todos os dados adquiridos foram divididos em três bancos de dados. Mas recortes e vieses são feitos ao longo de uma pesquisa: dois desses bancos não eram relevantes 
para a investigação em questão. ${ }^{6}$ No banco de dados utilizado foram armazenados 300 verbos com suas análises temáticas e os exemplos de propriedades e fatores envolvidos na seleção argumental desses verbos. Essas propriedades foram tiradas da literatura na área como sendo relevantes para o estudo dos verbos psicológicos (Belletti \& Rizzi, 1988; Levin, 1989; Whitaker-Franchi, 1989; Grimshaw, 1990; Franchi, 1992). Mas para estudar a rede temática desses verbos, deparei-me com a seguinte questão: com que papéis temáticos e sob que critérios de delimitação devo trabalhar? Nesse ponto adotei uma direção inversa à adotada por Dowty (1991), que restringe os papéis temáticos a serem investigados, e segui Franchi (1992), optando por uma classificação mais fina desses papéis. Optei por essa classificação, diferentemente do que se encontra em grande parte da literatura, por não achar que a redução localista se possa sustentar. $\mathrm{E}$, opostamente a GB, por acreditar (e ter encontrado evidências) na relevância do conteúdo de diferenciados papéis temáticos na estruturação sintática.

\section{AS PROPRIEDADES SINTÁTICAS}

As propriedades sintáticas utilizadas para a análise descritiva dos verbos psicológicos foram as seguintes:

- a capacidade de o verbo aceitar construções ergativas;

- a capacidade de o verbo aceitar o que chamo de causativização, com a promoção do terceiro argumento (Cau ou Ins) para a posição de sujeito;

- a capacidade de o verbo aceitar a inversão dos dois últimos argumentos, a que chamo de "inversão".

Além destas propriedades, foram examinados os testes propostos por Belletti e Rizzi (1988) em seu estudo sobre os verbos psicológicos do italiano:

- se o verbo apresenta passivização sintática ou adjetiva; 
- se o verbo possui uma interpretação arbitrária quando temos pro como sujeito da oração;

- se o verbo permite orações causativas encabeçadas (utilizando-se do operador - fazer -). ${ }^{7,8}$

Essa análise foi feita a partir do cruzamento dos dados obtidos, e, de acordo com esses resultados, ou seja, o inventário das: propriedades e fatores sintáticos que envolvem a seleção argumental dos verbos psicológicos, estes foram divididos em quatro classes.

\subsection{Classe 1}

A Classe 1, que tem 48 verbos, representando $16 \%$ do total dos verbos estudados, será representada pelo verbo temer; é também encontrada na literatura como fear ou temere. As características principais apontadas são: apresentar o Exp na posição de sujeito e não permitir a ligação da anáfora contida no sujeito com o seu objeto. Levando-se em conta os dois argumentos nucleares (sujeito e objeto) e um argumento periférico causal (adjunto) pertinente para as outras propriedades estudadas, tem-se:

(9) José teme o cachorro pelo seu tamanho

$$
\operatorname{Exp} \quad \mathrm{Obj}_{\mathbf{i}} \quad \mathrm{Cau}_{\mathrm{i}}
$$

O exemplo em (9):

- não admite construções ergativas:

$(10)^{*} \mathrm{O}$ cachorro (se) teme pelo seu tamanho.

- não admite construções causativas:

(11)*O tamanho teme o cachorro.

- admite orações com inversão dos dois últimos argumentos:

(12) José teme o tamanho do cachorro.

- admite passivização sintática e não admite a adjetiva:

(13) a. O cachorro é temido por José.

b. ${ }^{*} \mathrm{O}$ cachorro ficava temido com José. 
- admite pro arbitrário como sujeito:

(14) Temem o cachorro pelo seu tamanho.

- admite oração causativa encabeçada:

(15) O amigo faz José temer o cachorro.

Além de temer, outros verbos que fazem parte desta classe são: abominar, admirar, adorar, amar, cobiçar, desejar, detestar, estimar, estranbar, bostilizar, invejar, menosprezar, odiar, recear, respeitar, subestimar, sublimar, venerar, etc.

\subsection{Classe 2}

À Classe 2, que é a mais numerosa, pertencem 130 verbos, $43 \%$ do total, e pode ser comparada à classe de preoccupare ou frighten ${ }^{9}$ encontrada na literatura. Esta classe distingue-se da Classe 1, primeiramente por apresentar o Exp na posição de objeto e permitir que uma anáfora contida no sujeito seja ligada ao seu objeto:

(16) Rosa preocupa a mãe com sua arrogância.

$$
\mathrm{Cau}_{\mathrm{i}} \quad \mathrm{Exp} \mathrm{Cau}_{\mathrm{i}}
$$

O exemplo em (16):

- admite ergatividade:

(17) A mãe (se) preocupava com a arrogância de Rosa.

- admite causatividade:

(18) A arrogância de Rosa preocupava a mãe.

- não admite inversão dos dois últimos argumentos:

(19)*Rosa preocupava a arrogância da mãe.

- admite passiva adjetiva, mas não admite passiva sint $\square$ tica:

(20) a. A mãe ficava preocupada com a arrogância de Rosa.

b."A mãe foi preocupada por Rosa.

- não admite pro arbitrário como sujeito:

(21) Preocupavam a mãe com aquela arrogância. 
- não admite oração causativa encabeçada:

(22)*O pai fazia Rosa preocupar a mãe.

Outros verbos pertencentes a esta classe são: abalar, aborrecer, acabrunbar, afligir, alucinar, azucrinar, baratinar, chatear, comover, decepcionar, deprimir, encantar, enfezar, escandalizar, grilar, borrorizar, inquietar, magoar, revitalizar, traumatizar, etc.

\subsection{Classe 3}

(23) A polícia acalma a multidão com seus cassetetes. Ag Exp Ins

A Classe 3, do verbo acalmar, é uma classe não apontada pela literatura. Os verbos pertencentes a ela, de acordo com a análise temática usada habitualmente e de acordo com os problemas apresentados quanto à ligação de anáforas, deveriam se encaixar na Classe 2. Mas achei um número suficiente de verbos, $35,12 \%$ do total, que se comportam sintaticamente de uma maneira diferente dos verbos da Classe 2. Essas propriedades são:

- admite construções ergativas:

(24) A multidão (se) acalma com os cacetetes da polícia.

- admite orações causativas:

(25) Os cacetetes da polícia acalmam a multidão.

- não admite orações com inversão dos dois últimos argumentos:

(26)*A polícia acalma os cacetetes da multidão.

- admite passiva sintática, mas não admite a adjetiva:

(27) a. A multidão foi acalmada pela polícia.

b. *A multidão ficou acalmada com os cacetetes da polícia.

- admite pro arbitrário com sujeito:

(28) Acalmaram a multidão com aquelas ameaças. 
- admite causativa encabeçada:

(29) O coronel fez a polícia acalmar a multidão.

Para uma possível evidência em inglês da hipótese de que existe uma terceira classe de psico-verbos, pode-se apontar alguns exemplos encontrados em Zubizarreta (1992):

(30) Mary was humiliated by John's remarks. 'Mary foi humilhada pelas observações de John.'

(31) Mary was inspired by the sunset. 'Mary foi inspirada pelo sol.'

Esses exemplos têm o Tema (segundo a autora) na posição de sujeito e aceitam passivização com o adjunto by; essa ocorrência pode ser uma evidência de que esses verbos aceitam passivização sintática, propriedade essa que não seria típica da Classe 2 , mas sim da Classe 3. Entretanto, seria necessário uma listagem mais exaustiva dos psico-verbos em inglês para se poder fazer tal afirmação.

Também fazem parte desta classe: abrandar, aplacar, conquistar, derrotar, desenganar, embromar, bonrar, bumilbar, martirizar, pacificar, provocar, reconfortar, serenar, suavizar, tranqüilizar, etc.

\subsection{Classe 4}

A classe do verbo animar, que representa $29 \%$ do total com 90 verbos, também se distingue da Classe 1 por apresentar o Experienciador na posição de objeto e permitir a ligação da anáfora contida no sujeito com seu objeto. Segundo a literatura, seria classificada como pertencente à Classe 2 . Entretanto, esses verbos aceitam tanto as propriedades sintáticas atribuídas à Classe 2 quanto as propriedades sintáticas atribuídas à Classe 3; a escolha dependerá da leitura agentiva ou não que se faz da oração. Por isso, a separei como uma classe distinta: 
(32) a. Maria animou José com seus argumentos.

$$
\text { Ag Exp Ins }
$$

b. Maria animou José com sua beleza.

$$
\mathrm{Cau}_{\mathrm{i}} \quad \mathrm{Exp} \mathrm{Cau}_{\mathrm{i}}
$$

- ergatividade:

(33) a. José (se) animou com os argumentos de Maria.

b. José (se) animou com a beleza de Maria.

- causativização:

(34) a. Os argumentos de Maria animaram José.

b. A beleza de Maria animou José.

- inversão dos dois últimos argumentos:

(35) a."Maria animou os argumentos de José.

b. Maria animou a beleza de José.

- passivas sintática e adjetiva:

(36) a. José foi animado por Maria.

b. José ficou animado com a beleza de Maria.

- pro arbitrário como sujeito:

(37) a. Animaram José com aqueles argumentos.

b. Animaram José com aquela beleza.

- oração causativa encabeçada:

(38) a. João fez Maria animar José com seus argumentos.

b. João fez Maria animar José com sua beleza.

Outros verbos dessa classe são: alarmar, apavorar, atormentar, consolar, desiludir, embaraçar, entusiasmar, fascinar, fortalecer, importunar, influenciar, intimidar, motivar, purificar, reanimar, etc.

No quadro geral a seguir, pode-se ver mais claramente o contraste entre as classes e as respectivas propriedades: 
(39)

\begin{tabular}{|c|c|c|c|}
\hline $\begin{array}{l}\text { Classe } 1 \\
\text { temer }\end{array}$ & $\begin{array}{l}\text { Classe } 2 \\
\text { preocupar }\end{array}$ & $\begin{array}{l}\text { Classe } 3 \\
\text { acalmar }\end{array}$ & $\begin{array}{l}\text { Classe } 4 \\
\text { animar }\end{array}$ \\
\hline Exp-suj & Exp-obj & Exp-obj & Exp-obj \\
\hline $\begin{array}{l}\text {-lig.anaf } \\
\text {-erg }\end{array}$ & $\begin{array}{l}\text { +lig.anaf } \\
+ \text { erg }\end{array}$ & $\begin{array}{l}\text { +lig.anaf } \\
+ \text { +erg }\end{array}$ & $\begin{array}{l}\text { +lig.anaf } \\
\text { +erg }\end{array}$ \\
\hline$-\mathrm{cau}$ & $+c a u$ & $+c a u$ & + cau \\
\hline +inv & -inv & -inv & -inv \\
\hline+ p.sin & + p.adj & + p.sin & + p.sin e adj \\
\hline+ pro & -pro & +pro & + pro \\
\hline +c.enc & -c.enc & +c.enc & +c.enc \\
\hline
\end{tabular}

Concluindo, a Classe 1 distingue-se das Classes 3 e 4 por: apresentar o Exp na posição de sujeito; não permitir o tipo de ligação de anáforas permitida às outras classes; e permitir a inversão dos dois últimos argumentos. As Classes 2 e 3 vão assemelhar-se quanto a: posição do Experienciador; tipo de ligação de anáforas permitida; aceitação de construções ergativas e causativas; não-aceitação da inversão dos dois últimos argumentos. Distinguem-se, todavia, quanto a: tipo de passivização; aceitação ou não do pro arbitrário como sujeito; aceitação de orações causativas encabeçadas. Portanto, o que se vê é que, diferentemente do que é mostrado para outras línguas, o português (segundo a posição do Exp e certas propriedades sintáticas) separa os verbos psicológicos em quatro classes distintas. Dessa classificação, surgem novas questões sobre os psico-verbos a serem examinadas, além das questões já citadas na literatura:

- Por que a Classe 1 não aceita ergativização e causativização e as outras classes aceitam?

- Por que pode ocorrer a inversão dos dois últimos argumentos, o complemento e o adjunto, na Classe 1, e nas outras não é possível?

- Por que as Classes 1, 3 e 4 aceitam pro como sujeito, construções causativas encabeçadas e passivização sintática contrariamente à Classe 2 ?

Para investigar tais questões, usarei, pois, a análise das relações temáticas desses verbos. 


\section{ALGUMAS CONSIDERAÇŌES SOBRE PAPÉIS TEMÁTICOS}

Antes de passar para a análise temática dos dados, farei algumas breves considerações. Primeiramente, como o escopo deste artigo não atinge questões teóricas acerca das relações temáticas, limitar-me-ei a caracterizar os papéis temáticos utilizados na descrição da rede temática dos psico-verbos com uma espécie de "lista de traços". Embora as caracterizações que aqui serão apresentadas sejam descritivas, são baseadas em Cançado (1995a), onde os papéis temáticos possuem estatuto teórico e são definidos formalmente via acarretamentos lexicais .

Justificarei também a escolha de uma classificação mais fina, não localista, dos papéis temáticos. Jackendoff (1972), nas primeiras versões de seu modelo, desenvolve a intuição de Gruber (1965) de que a estruturação de campos semânticos não espaciais é uma extensão da estrutura conceitual da locação e do movimento. Por exemplo, o papel temático de Experienciador seria tratado como Locativo ou Meta: o "lugar" em que se dá o medo/ prazer/ preocupação ... (ver também Ruwet (1972)). Trata-se de uma aparente generalização: os argumentos e posições sintáticas associados a esses papéis possuem distintas propriedades sintáticas. Basta notar que ocupam posições distintas na hierarquia temática que estabelece a ordenação dos argumentos na estrutura sintática; o Experienciador (como objeto afetado ou estativo), e não o Locativo, ocupa normalmente posições de sujeito e objeto:

(40) a. Paulo assustou o filho no quarto escuro.

b. Longe do pai, o filho de Paulo tem medo do escuro.

E' o caso também do Tema: objeto locado ou em movimento. Uma hipótese localista levaria a atribuir o mesmo papel Tema a vaso de barro em:

(41) a. José quebrou o vaso de barro.

b. José encheu o vaso de barro com terra vegetal. 
c. José modelou um vaso de barro.

d. José colocava o vaso de barro na estante.

Essa análise perde a diferença fundamental entre os traços de afetação do objeto em (a), condição necessária à classe dos verbos "ergativos" (Whitaker-Franchi, 1989), ausentes em (b), (c) e (d):

(42) a. O vaso quebrou/??encheu com terra vegetal. b. ${ }^{*} \mathrm{O}$ vaso modelou/colocava na estante.

Esse tipo de concepção levou a um uso extensivo dessa etiqueta entre os gerativistas para designar papéis temáticos determinados por propriedades semânticas muito distintas. Esse é o caso das redes temáticas propostas na literatura, mostradas em (1) e (2) (ou, por exemplo, Belletti e Rizzi, 1988; e, de uma certa maneira, Grimshaw, 1990). Uma espécie de "papel temático-default", impossível de caracterizar-se. ${ }^{10}$ Por essas razões, adotou-se, neste trabalho, a classificação que será mostrada a seguir.

Dowty (1989) entende "papel temático", informalmente, como uma família de acarretamentos e pressuposições partilhados por argumentos determinados de certos verbos. Acrescentarei a essa definição que esses papéis ainda admitem alguns traços não necessariamente acarretados pela relação semântica desse argumento com o verbo, mas somente compativeis com essa relação. Portanto, os papéis temáticos serão aqui listados em termos de acarretamentos e compatibilidades.

\subsection{Agente}

Pode-se definir um papel temático Agente para um argumento $\mathrm{x}$, sempre que entre as propriedades acarretadas pela relação de $\mathrm{x}$ com um predicado a, estiverem as de:

- ter algum papel no desencadeamento do processo;

- fazê-lo intencionalmente (no sentido de Davidson (1980): se um evento é uma ação, sob alguma descrição, é uma "ação primitiva" e "intencional". E um elemento é um agente se, sob alguma descrição, seja direta, seja pelas suas conseqüências, 
ele é responsável intencionalmente por essa ação mesmo quando não o seja pelas suas conseqüências; para discussões mais detalhadas sobre essa propriedade, ver Cançado, 1995a).

Derivado desta propriedade, tem-se:

- ser animado e ter controle sobre o processo.

\subsection{Causa}

Parto do pressuposto, baseada em razões que seriam muito extensas para este artigo, que os papéis temáticos de Agente e Causa são distintos, embora haja traços semânticos comuns que os aproximem. Esse papel caracteriza-se quando o predicado acarreta a propriedade:

- ter um papel no desencadeamento do processo ou na manutenção de um estado.

\subsection{Objetivo} de que:

O papel temático Objetivo é claramente estativo, no sentido

- entra em uma relação com o predicador que não implica mudança de estado.

\subsection{O Experienciador}

O Experienciador caracteriza-se por designar um papel temático determinado pelo predicador de modo a:

- estar em um estado psicológico, seja no sentido estativo, seja no sentido processual de que passou por um processo de mudança para entrar nesse estado. Derivado desta, tem-se:

- ser animado.

E também é compatível com os traços:

- ser afetado por um processo;

- ter o controle de sua própria experiência psicológica. 


\section{A REDE TEMÁTICA DOS PSICO-VERBOS}

Analisarei a rede temática das quatro classes dos psico-verbos do português, utilizando para isso a lista de acarretamentos e compatibilidades dada acima.

\subsection{Classe 1}

Para o verbo temer, o primeiro argumento, por estar em determinado estado psicológico, é o Experienciador. E o segundo argumento é o papel temático Objetivo, pois esse entra em uma relação com o verbo que não acarreta nenbuma mudança de estado:

(43) a. José teme o cachorro.

$$
\text { Exp Obj }
$$

b. TEMER: \{Exp, Obj\}

Ainda se pode acrescentar que o argumento Exp deste verbo, para o português pelo menos, parece ser compatível com o traço de tero controle sobre sua própria experiência. É fácil constatar que certas construções, passíveis de terem um certo controle, são perfeitamente boas para os verbos da Classe 1; já essas mesmas construções com verbos que não apresentam o traço de controle não são boas frases do português:

(44) a. Daqui para frente, eu vou parar de temer fantasmas.

b. Ame o próximo como a si mesmo.

c. Daqui para frente, eu vou parar de quebrar a perna.

d. Tenha casas neste bairro.

\subsection{Classe 2}

$O$ argumento que ocupa a posição de sujeito nessa classe entra em uma relação com o verbo a que acarreta: ter um papel no 
desencadeamento do processo; portanto, é uma Causa. Embora distinta da de outros autores, essa classificação encontra evidências empíricas na morfologia do japonês, também coincidindo com a classificação dada por Pesetsky (1987, em prep.), e de uma certa forma com a análise temático-aspectual de Grimshaw (1990). O argumento interno será ocupado pelo Experienciador pois preocupar acarreta para esta posição ser afetado pelo processo em um determinado estado psicológico:

(45) a. Rosa preocupava a mãe. Cau Exp

b. PREOCUPAR: \{Cau, Exp\}

\subsection{Classe 3}

Para o exemplo (46), esta classe admite a mesma rede temática da classe de preocupar:

(46) A chegada da polícia acalma a multidão. Cau Exp

Mas, em uma análise mais detalhada dos exemplos, vê-se que, além das relações de Causa e Exp vistas acima, esses verbos também aceitam outros tipos de relações semânticas, como a Agentividade ou um Instrumento na posição de sujeito:

(47) A polícia acalma a multidão com seus cassetetes Ag Exp Ins

(48) Os cassetetes da polícia acalmaram a multidão. Ins $\operatorname{Exp}$

Isso implica que, além de desencadear um processo, a relação do argumento polícia (em relação composicional com cassetetes) com o verbo acalmar acarreta ter intenção no processo (no sentido de Davidson); derivado desta, também temos o traço ser animado. Diferentemente do que ocorre com a Classe 2 que não permite 
leitura agentiva, mesmo que o argumento-sujeito seja animado (lembre-se que esta propriedade não é acarretada pelo verbo preocupar):

(49) João acalma Maria com um chá. (A ação intencional de João em relação a Maria faz Maria acalmar-se.)

(50) João preocupa Maria com sua chegada. ("A ação intencional de João em relação a Maria faz Maria preocupar-se.)

Uma observação importante a ser feita é que não se pode confundir a natureza agentiva de um verbo com o traço [+intenção] relacionado às consequiências da ação praticada. ${ }^{11}$ Segundo Belletti \& Rizzi (1988), "com alguns verbos da classe de preoccupare, um sujeito humano pode ser interpretado como indutor voluntário do processo ou estado do Exp, pragmaticamente mais natural quando está envolvida alguma reciprocidade ajudada por advérbios como voluntariamente, intencionalmente. Nesses casos, o sujeito é um simples sujeito agentivo profundo, e alguns dos testes propostos serão aceitos pelo sujeito". Isso não é verdade; os verbos da Classe 2 podem ter uma leitura implicando a intencionalidade no resultado do processo com sujeitos humanos e, ainda nessas condições, não têm uma leitura agentiva. Vejamos os exemplos abaixo:

(51) a. Maria, intencionalmente, preocupa a mãe com suas saídas.

b.*A ação intencional de Maria sobre a mãe a preocupa.

c. O fato de Maria sair preocupa a mãe; e Maria o faz intencionalmente.

Ainda um outro traço que se pode acrescentar da relação agentiva de policia com acalmar em (47) é o fato de policia ter o traço de controle sobre sua ação.

Como esses três papéis admitidos pela Classe 3 têm em comum o acarretamento ter papel no desencadeamento do processo, darei 
o nome de CAUSA a este macropapel, querendo significar que este verbo aceita tanto uma Causa, quanto um Agente ou um Instrumento em sua posição de sujeito:

(52) ACALMAR: \{CAUSA, Exp\}

\subsection{Classe 4}

Como já foi mostrado na seção anterior, a diferença desta classe para a Classe 3 não está em sua rede temática, mas, sim, em suas propriedades sintáticas pois, além de aceitar a rede temática atribuída à Classe 3, também permite todas as propriedades sintáticas atribuídas às Classes 2 e 3:

(53) a. Maria animou José.

Ag $\quad \operatorname{Exp}$

b. A chegada de Maria animou José.

Cau Exp

c. Um chá animou Maria. Ins Exp

d. ANIMAR: \{CAUSA, Exp\}

Encerrando essa seção, torno a mostrar a classificação temática dada às quatro classes propostas:

(54) a. TEMER: \{Exp, Obj]\}

b. PREOCUPAR: \{Cau, Exp\}

c. ACALMAR/ANIMAR: \{CAUSA, Exp\}

\section{INDÍCIOS DE LIGAÇĀO ENTRE A SINTAXE E A SEMÂNTICA}

A análise dos dados mostrados levou-me a assumir certas posições que explicitarei a seguir. Antes porém quero relatar um outro processo que também contribuiu para as conclusões que serão relatadas aqui. De posse dos dados acima, apliquei os resultados em 
três propostas existentes na literatura. Constatei que a proposta sintática inacusativa de Belletti \& Rizzi (1988) não se sustenta para os dados do português (ver Cançado, no prelo). Tampouco a proposta sintático-aspectual de Grimshaw (1990) ou a proposta aspectual de Van Voorst (1992) conseguem explicar as questões surgidas nessa análise (ver Cançado, 1995b). Não se comprovando diferenças a nível da configuração sintática e nem a nível aspectual entre as classes dos verbos psicológicos, deve-se buscar a solução para os problemas apresentados por esses verbos em um outro plano. Observo que a adoção de uma classificação mais fina dos papéis temáticos levou a diferentes redes temáticas para as classes dos psico-verbos. Portanto, é plausível supor que os diferentes comportamentos e propriedades apresentados por esses verbos têm sua origem em suas diferenças semânticas.

Seguindo as questões colocadas no final da seção 4 , levanto as seguintes hipóteses que foram de uma certa forma corroboradas formalmente em Cançado (1995a) dentro do quadro da Teoria Generalizada dos Papéis Temáticos (Franchi apud Cançado, 1995a). As diferentes realizações sintáticas dessas classes devem-se ao fato de elas possuírem diferentes papéis em suas redes temáticas e esses papéis estarem submetidos a um princípio de hierarquia temática que faz a correspondência entre a semântica e a sintaxe.

Uma segunda hipótese levantada é que o fato de as Classes 1,3 e 4 apresentarem a passiva sintática e aceitarem orações causativas encabeçadas deve-se a elas terem o traço semântico [+controle] presente em seus argumentos localizados na posição de sujeito; o que não ocorre na Classe 2 onde esse traço é inexistente. Vejamos alguns exemplos com outros tipos de verbos que nas sentenças mostradas teriam, supostamente, este traço no argumentosujeito, e aceitam a passiva:

(55) a. João recebeu a herança de sua tia.

b. A herança foi recebida por João.

c. A mãe fez João receber aquela herança. 
(56) a. João quebrou o vaso com um martelo.

b. Este vaso foi quebrado por João com um martelo.

c. A namorada fez João quebrar o vaso com um martelo.

E vejamos os exemplos em que parece não existir o traço de controle presente na posição de sujeito das sentenças:

(57) a. João recebeu uma rasteira do colega.

b. A rasteira foi recebida por João.

c.*A mãe fez João receber a rasteira.

(58) a. João quebrou o vaso com o empurrão que o colega lhe deu.

b.??O vaso foi quebrado por João com o empurrão que o colega lhe deu.

c.*A namorada fez João quebrar o vaso com o empurrão.

Quanto à aceitação da ergativização/causativização apresentada nos exemplos, Whitaker-Franchi (1989) já havia mostrado que:

- não é possível se o evento pressupõe agentividade do argumento externo;

- o argumento interno tem que ter o traço de objeto afetado (também Levin (1989) impõe essa condição).

Essa última condição explica a impossibilidade de a Classe 1 aceitar tais propriedades, pois o papel temático de Objetivo não acarreta e nem é compatível com esse traço. Já, para as outras três classes, o Exp que ocupa a posição de argumento interno é afetado pelo processo, daí a possibilidade de ergativização.

A questão de as classes aceitarem um pro arbitrário na posição de sujeito parece também estar ligada ao traço semântico [+animado]. E a condição implícita no fato de poder haver uma inversão entre os dois últimos argumentos da Classe 1 é a de que entre o argumento selecionado e o elemento em adjunção exista uma relação semântica que possibilite a transitividade. 
Uma última questão relaciona-se ao fenômeno da ligação de anáforas com o antecedente localizado no objeto. Esta possibilidade está limitada aos verbos das Classes 2, 3 e 4 (pois o verbo temer toma $o$ argumento-Experienciador na posição de sujeito). Ressalto que este fato foi a motivação mais forte da proposta de Belletti e Rizzi para os psico-verbos. Mas, no decorrer dessa pesquisa, observei que a ligação excepcional da anáfora não tem qualquer relação com o fato de o verbo ser psicológico. Vejamos alguns exemplos:

(59) A consciência de si próprio ajuda muito o professor.

(60) A severa disciplina consigo mesmo torna Paulo um professor autoritário.

(61) A insegurança em si mesmo levou João à falência.

(62) A excessiva confiança em si mesmo custou a vida de Sam.

O que aproxima os verbos dessas orações aos verbos das classes 2, 3 e 4 é o fato de que o argumento-sujeito se caracteriza tematicamente como Causa (com verbos da classe \{CAUSA, ...\}. Estive tentada a propor uma hipótese explorando a proeminência de Causa na Hierarquia Temática. Mas essa hipótese não resistiu aos contraexemplos. Há outros predicadores que podem selecionar um sintagma complexo na posição de sujeito, sem que the seja associado um papel temático Causa:

(63) A confiança em si mesmo é a virtude mais evidente de João.

(64) O descuido consigo mesmo se inclui entre os defeitos de Sam.

(65) As estórias sobre si mesmo têm a aprovação do vaidoso mestre.

Dada a enorme variedade dos papéis temáticos envolvidos, qualquer hipótese que envolva uma noção como a de hierarquia temática não se sustentaria, remetendo-nos assim de volta à teoria 
da vinculação para explicar a ligação excepcional da anáfora (Ver Cançado, 1996).

\section{SÍNTESE FINAL}

Primeiramente, este artigo fez uma ampla revisão das propriedades sintáticas e semânticas dos verbos psicológicos. Como essa classe de verbos apresenta interessantes propriedades relacionadas à organização da estrutura argumental, espero que a apresentação desses resultados levante o interesse de pesquisadores na área, e que outras abordagens teóricas sejam propostas para os dados do português.

Também propus um outro tipo de classificação para esses verbos, baseada em uma análise semântica mais fina dos papéis temáticos. Essa nova classificação, em comparação com a análise das propriedades sintáticas apresentadas, levou-me a indícios de que algumas das questões sintáticas levantadas podem ser explicadas semanticamente ou podem sofrer algumas restrições dessa natureza.

\section{NOTAS}

' Este trabalho é parte da minha tese de Doutorado, feita sob a orientação do Prof. Dr. Carlos Franchi.

${ }^{2} \mathrm{O}$ conjunto total desses dados encontra-se em Cançado (1995a).

${ }^{3}$ Seleção argumental, como Dowty (1991) chama, ou mudança nas funções gramaticais, como eram conhecidas nas Gramáticas de Casos, são os princípios que as línguas naturais usam para determinar quais papéis temáticos estão associados a quais argumentos de um predicado, incluindo aí, não somente a seleção do sujeito (como era feito na Gramática de Casos), mas também a seleção de complementos e adjuntos.

${ }^{4}$ A diátese de um verbo expressa as relações semânticas que esse verbo tem com seus argumentos (ver Capítulo 4, Cançado, 1995a). 
s Trata-se de um útil instrumento para o trabalho pela abundante exemplificação de variadas fontes, abonada por um numeroso corpo de colaboradores com experiência lingüística.

${ }^{6}$ Em um banco de dados, fez-se um estudo sobre a nominalização desses verbos e papéis temáticos apresentados. Não há relevância no momento para esse estudo; servirão para outra pesquisa.

Em um outro banco de dados, simplesmente foram listados 60 verbos que apresentam um argumento externo e outro preposicionado:

(i) Glória antipatizou com João.

Exp Obj

Esses verbos não serão estudados neste trabalho por apresentarem uma rede temática diferente dos outros 300 verbos, dificultando assim uma comparação entre eles.

7 Também foi testada a capacidade do verbo de ligar um clítico reflexivo, propriedade estudada por Belletti \& Rizzi, mas, para o português, não foi possível chegar a generalizações a partir desses dados.

${ }^{8}$ Um último teste, que também não acrescentou muito à análise, foi: qual preposição introduzia o terceiro argumento. $O$ resultado foi que um adjunto causal que tem relação de antecedência com o sujeito pode ser introduzido pela preposição com ou por:

(i) a. Rosa preocupava a mãe com sua arrogância.

b. Rosa preocupa a mãe por sua arrogância.

Se o adjunto causal não tiver relação com o sujeito ele só pode ser introduzido pela preposição por:

(ii) a. João temia o cachorro pelo seu tamanho.

b. "João temia o cachorro com seu tamanho.

$\mathrm{E}$, se o terceiro argumento for um instrumento, ele só pode ser introduzido pela preposição com:

(iii) a. Maria acalmava o tenente com um chá.

b. Maria acalmava o tenente por um chá.

${ }^{9}$ A tradução de frighten para o português, assustar, não se encaixa na Classe 2, mas sim na Classe 4.

${ }^{10}$ O próprio Jackendoff (1987 e 1990) reconhece, posteriormente, a inadequação de se adotar uma hipótese estritamente localista e divide os papéis temáticos em dois planos (tiers): o temático, com uma concepção localista, e um segundo, paralelo ao plano temático, o plano da ação, em que se recuperam noções como as de Agente, Paciente, Instrumento. 
${ }^{11}$ Como já ressaltei, Davidson (1980), em sua definição de intencionalidade, diferencia a intenção de um Agente quando ele pratica uma ação, da intenção de um Agente no que diz respeito às conseqüências dessa ação.

\section{REFERÊNCIAS BIBLIOGRÁFICAS}

BAKER, M. (1988). On the Theta Roles of Psych Verbs. Manuscript. Mc Gill University.

BELLETTI, A. \& RIZZI, L. (1988). Psych Verbs and Theta-Theory. Natural Language and Linguistic Theory 6: 291-352.

BORBA, F. S. e outros (1990). Dicionário Gramatical de Verbos do Português Contemporâneo do Brasil. São Paulo: Editora da Universidade Estadual Paulista.

CANÇADO, M. (1995a). Verbos Psicológicos: A Relevância dos Papéis Temáticos vistos sob a Ótica de uma Semântica Representacional.Tese de Doutorado. IEL. UNICAMP. . (1995b). A Teoria da Proeminência de Grimshaw e os Psico-Verbos do Português Brasileiro. D.E.L.T.A. 11.2: 279-299 . (no prelo). Os Psico-Verbos do Português Brasileiro e a Análise Inacusativa de Belletti \& Rizzi: Indícios para uma Proposta Semântica. D.E.L.T.A. . (1996). Ligação Excepcional de Anáforas. Manuscrito. UFMG.

DAVIDSON, D. (1980). Actions and Events. New York: Oxford University Press.

DOWTY, D. R. (1989). On the Semantic Content of the Notion of Thematic Role. In: Chierquia, Partee e Turner (eds.): 69-129.

. (1991). Thematic Proto-Roles and Argument Selection. Language 67: 547-619.

FERREIRA, A. B. H. e outros (1975). Novo Dicionánio Aunélio. Rio de Janeiro: Editora Nova Fronteira.

FRANCHI, C. (1975). Hipóteses para uma Teoria Funcional da Linguagem. Tese de Doutorado. IEL. UNICAMP.

. (1992). Relações Semânticas e Estruturas Oracionais. Manuscrito.

GRIMSHAW, J. (1987). Psych Verbs and the Structure of Argument Structure. Manuscript. Brandeis University. . (1990). Argument Structure. Cambridge (MA): MIT Press. 
GRUBER, J. S. (1965). Studies in Lexical Relations. Tese de Doutorado. MIT; reeditado como parte de Lexical Structures in Syntax and Semantics. Amsterdam: North Holland, 1976.

JACKENDOFF, R. (1972). Semantic Inteppretation in Generative Grammar. Cambridge (MA): MIT Press. . (1987). The Status of Thematic Relations in Linguistic Theory. Linguistic Inquiry 18: 369-411.

. (1990). Semantic Structures. Cambridge (MA): MIT Press.

LEGENDRE, G. (1989). Inversion with Certain French Experiencer Verbs. Language 65: 752-782.

LEVIN, B. (1989). Towards a Lexical Organization of English Verbs. Evanston: Northwestern University.

OLIVEIRA, M. E. M. (1979). Syntaxe des Verbes Psychologiques du Portugais. Tese de Doutorado. Université de Paris VII. Reeditado em Textos de Lingüústica 7. Lisboa: Instituto Nacional de Investigação Científica. Centro de Lingüística da Universidade de Lisboa (1984).

PESETSKY, D. (1987). Binding Problems with Experiencer Verbs. Linguistic Inquiry 18: 126-140.

. (in prep.). Experiencer, Predicates and Universal Alignment Principle. Department of Linguistics and Philosophy. MIT.

POSTAL, P. (1971). Cross-Over Phenomena. New York: Holt, Rinehart and Winston.

RUWET, N. (1972). A propos d'une Classe de Verbes Psychologiques. Théorie Syntaxique et Syntaxe du Français. Paris: Editions du Seuil.

VAN VOORST, J. (1992). The Aspectual Semantics of Psychological Verbs. Linguistics and Philosophy 15: 65-92.

WHITAKER-FRANCHI, R. C. M. (1989). As Construções Ergativas: Um Estudo Sintático e Semântico. Tese de Mestrado. IEL, Unicamp.

ZUBIZARRETA, M. L. (1992). The Lexical Encoding of Scope Relations among Arguments. IN: E. Wehrli and T. Stowell (eds.), 211-258. 